\title{
Optimal Income Taxation with a Risky Asset - The Triple Income Tax
}

\author{
Dirk Schindler* \\ Universität Konstanz ${ }^{\dagger}$
}

December 15, 2003

\begin{abstract}
We show in a two-period world with endogenous savings and two assets, one of them exhibiting a stochastic return that an interest adjusted income tax is optimal. This tax leaves a safe component of interest income tax free and taxes the excess return with a special tax rate. There is no trade off between risk allocation and efficiency in intertemporal consumption. Both goals are reached. As the resulting tax system divides income into three parts, the tax can also be called a triple income tax. This distinction and a special tax rate on the excess return is necessary in order to have an optimal risk shifting effect.
\end{abstract}

\section{JEL-Classification: $\mathrm{H} 21$}

Keywords: Optimal Taxation, Uncertainty, Consumption Tax, Triple Income Tax

*I am very grateful to Markus Beslmeisl, Bodo Hilgers, Dirk Kiesewetter and Mathias Kifmann for valuable comments. The paper benefitted also from discussions with participants of the Public Finance workshop at CESifo, Munich. Any remaining errors are my own. The author acknowledges financial support from the Volkswagen-Stiftung.

${ }^{\dagger}$ Corresponding author: Dirk Schindler, Universität Konstanz, Fach D 133, 78457 Konstanz, Germany; Email: Dirk.Schindler@uni-konstanz.de; Phone +49-7531-883691, Fax +49-7531884101 . 


\section{Introduction}

In a world without uncertainty and distributional considerations the optimal tax structure for financing public expenditure is lump sum. In case of uncertainty about the individual wage rate, so called private risk, this statement does not hold. Eaton and Rosen (1980) showed in their seminal paper that for a one-period world with endogenous labor choice an income tax with a strictly positive marginal tax rate improves welfare. The government pools the private risk of all individuals and uses a lump sum transfer in order to return the tax revenue. The income tax takes the function of a social insurance scheme against private risk. Varian (1980) showed similar effects for a two-period world where the households work for a known wage rate and have to choose between consumption and savings. In his analysis, individuals face private risk because of uncertainty about the best investment portfolio.

Richter and Wiegard (1991) examine a model with aggregate risk and endogenous savings. In their two-period model the households have inelastic labor supply in period zero and divide their exogenous labor income between consumption and savings. Consumption in the following period is financed by savings and a stochastic interest income. Richter and Wiegard show that a tax on this risky interest income improves welfare under certain conditions. The optimal tax rate is a trade-off between efficiency and insurance. Therefore, it depends on the elasticity of current consumption with respect to a compensated relative change of the tax rate. Further they show that a consumption tax cannot achieve this insurance function. Related studies have been done by Richter (1992). He examines the portfolio choice decision in a two asset world with one exhibiting a stochastic return and one safe asset. Richter develops an optimal elasticity rule for the taxation of asset returns and demonstrates that a cash flow tax is not optimal, if tax rates are not differentiated.

These results suggest that in case of uncertainty a consumption tax is always inferior compared to an income tax. This is because an income tax provides superior insurance by taxing capital income and the sacrifice of a distorted intertemporal consumption decision is more than compensated by the reduction of risk. 
But, we show in our paper that this sacrifice is not necessary. First, by using a adequately defined tax system, we can achieve both insurance and intertemporal efficiency. Second, we are able to show, that the resulting optimal tax scheme is a modern form of consumption taxation. Precisely, we will get a kind of consumption-orientated income tax with interest adjustment (see i.e., Rose 1999, pp. $35 \mathrm{ff}$ ). In contrast to Richter and Wiegard, we can state that a consumption tax is able to insure against risk in capital income.

The remainder of the paper will be as follows. In section 2 we present the model and examine the household choice, whereas section 3 discusses the optimal tax structure for a welfare maximum. The paper closes with some conclusions.

\section{The Model and Household Choice}

As in Richter and Wiegard (1991), we use a two-period model without any bequest motive. There is a homogenous individual, receiving exogenous labor income $y$ in period one and dividing it on first period consumption $c_{0}$ and savings $s_{0}$. Savings can be invested in an asset $A_{0}$ with a certain return $r>0$ and in a risky asset $A_{1}$, which has a stochastic return $\tilde{x} \geq-1$. We assume $E[\tilde{x}]>r$. Savings are the only source of consumption in the second period.

The government can use both a proportional wage tax $t^{L}$ in the first period ${ }^{1}$ and a tax on interest income. For capital income taxation we follow the approach of Hilgers and Schindler (2002) and use a two-part interest income tax. We tax the safe return $r$ in both assets with rate $t_{0}$ and the "excess return" $(\tilde{x}-r)$ with rate $t_{1}$ and assume full loss offset. If the realization of the excess return is negative, this loss will lead to a tax refund of $t_{1} \cdot(\tilde{x}-r)$. All tax revenue is used to finance a public good $g$ in period $1 .^{2}$

The savings can now be written as $s_{0}=A_{0}+A_{1}=\left(1-t^{L}\right) y-c_{0}$. Consumption in period 1 is $\tilde{c}_{1}=\left[\left(1-t_{1}\right)(\tilde{x}-r) A_{1}+\left[1+r\left(1-t_{0}\right)\right]\right]\left(\left(1-t^{L}\right) y-c_{0}\right)$. We assume

\footnotetext{
${ }^{1}$ This wage tax is equivalent to a lump sum tax.

${ }^{2}$ In the Hilgers/Schindler model there is no labor income, but the tax system for capital income is equivalent. The idea is having enough instruments for pursuing two goals, namely an optimal resource allocation as well as an efficient risk diversification.
} 
that the representative investor is risk averse in both private and public consumption. The von Neumann-Morgenstern utility function is additive separable and takes the form

$$
W=E\left[U\left(c_{0}, \tilde{c}_{1}\right)\right]+E[V(\tilde{g})] \text { with } U_{c}>0 ; U_{c c}<0 ; V_{g}>0 ; V_{g g}<0 .
$$

Unlike Richter and Wiegard we do not take $E[\tilde{g}]$ as given. In this model, the government chooses the tax rates and the tax revenue is used completely to finance the public good. Therefore, the probability distribution of $\tilde{g}$ is also an instrument variable of the government.

The household maximizes his expected utility $W$ for given tax rates by choosing his optimal first period consumption $c_{0}$ and his optimal savings $A_{0}+A_{1}=$ $\left(1-t^{L}\right) y-c_{0}$ with respect to his budget constraint. He does not anticipate the effect of his saving behavior on the level of the public good. Inserting the budget constraint for $\tilde{c}_{1}$, the maximization problem can be written as

$$
\max _{c_{0}, A_{1}} W=E\left[U\left(c_{0},\left(1-t_{1}\right)(\tilde{x}-r) A_{1}+\left[1+r\left(1-t_{0}\right)\right]\left(\left(1-t^{L}\right) y-c_{0}\right)\right]+E[V(\tilde{g})] .\right.
$$

The first order conditions of the household problem are:

$$
\begin{aligned}
& \frac{\partial W}{\partial c_{0}}=E\left[U_{c_{0}}\right]-E\left[U_{c_{1}} \cdot\left[1+r\left(1-t_{0}\right)\right]\right]=0 \\
& \frac{\partial W}{\partial A_{1}}=\left(1-t_{1}\right) E\left[U_{c_{1}} \cdot(\tilde{x}-r)\right]=0
\end{aligned}
$$

Optimal values of $c, A_{1}$ and $s$ are denoted $c_{0}=c_{0}\left(t_{0}, t_{1}, t^{L}\right), A_{1}=A_{1}\left(t_{0}, t_{1}, t^{L}\right)$ and $s_{0}=s_{0}\left(t_{0}, t_{1}, t^{L}\right)$. For the marginal rate of time preference we obtain:

$$
\rho=\frac{E\left[U_{c_{0}}\right]}{E\left[U_{c_{1}}\right]}-1=r\left(1-t_{0}\right)
$$

Equation (3) indicates that our tax system does not distort portfolio choice, as the FOC is equal to the optimality condition in case of no taxation.

\section{Proposition 1:}

The tax rate $t_{1}$ on the excess return $(\tilde{x}-r)$ does not affect overall savings $s_{0}\left(t_{0}, t_{1}, t^{L}\right)$ as $\frac{\partial c_{0}}{\partial t_{1}}=0$. Further, $t_{1}$ has only a substitution effect on $A_{1}$ and $\frac{\partial A_{1}}{\partial t_{1}}=\frac{A_{1}}{1-t_{1}}$. 


\section{Proof:}

Let $p_{r}=1+r\left(1-t_{0}\right)$ and $p_{A}=\left(1-t_{1}\right)(\tilde{x}-r)$. Totally differentiating equations (2) and (3) with respect to $c_{0}, A_{1}$ and $t_{1}$ gives:

$$
\begin{aligned}
& \left(\begin{array}{cc}
E\left[U_{c_{0} c_{0}}-U_{c_{0} c_{1}} p_{r}-U_{c_{1} c_{0}} p_{r}+U_{c_{1} c_{1}} p_{r}^{2}\right] & E\left[U_{c_{0} c_{1}} p_{A}-U_{c_{1} c_{1}} p_{r} p_{A}\right] \\
E\left[U_{c_{1} c_{0}} p_{A}-U_{c_{1} c_{1}} p_{A} p_{r}\right] & E\left[U_{c_{1} c_{1}} \frac{p_{A}^{2}}{1-t_{1}}\right]
\end{array}\right) \cdot\left(\begin{array}{c}
d c_{0} \\
d A_{1}
\end{array}\right)= \\
& =\left(\begin{array}{c}
E\left[U_{c_{0} c_{1} \frac{p_{A}}{1-t_{1}}}-U_{c_{1} c_{1}} p_{r} \frac{p_{A}}{1-t_{1}}\right] \\
E\left[U_{c_{1} c_{1}} \frac{p_{A}^{2}}{\left(1-t_{1}\right)^{2}}\right]
\end{array}\right) \cdot A_{1} \cdot d t_{1}
\end{aligned}
$$

Using Cramer's Rule, we get $\frac{\partial c_{0}}{\partial t_{1}}=0$, as the modified determinant det $\alpha_{d t_{1} A_{1}}$ in the nominator equals zero, and $\frac{\partial A_{1}}{\partial t_{1}}=\frac{A_{1}}{1-t_{1}}$ as $\operatorname{det} \alpha_{c_{0} d t_{1}}=\operatorname{det} \alpha_{c_{0} A_{1}} \cdot \frac{A_{1}}{1-t_{1}}$.

This result corresponds to the Sandmo result for taxing capital gains ${ }^{3}$ and is similar to the portfolio choice result for a net tax in case of several risky assets (Sandmo 1977). As investing more in the risky asset according to $\frac{\partial A_{1}}{\partial t_{1}}=\frac{A_{1}}{1-t_{1}}$ and diminishing the investment in the safe asset by the same amount and therefore keeping both first period and second period consumption constant, the tax rate change in $t_{1}$ does not change expected utility of the household.

\section{Optimal Taxes on Interest Income}

Assume that the tax revenue of the wage tax in period 0 is invested only in the safe asset. Thus, in period 1 , the budget restriction can be written:

$$
\tilde{g}=(1+r) t^{L} \cdot y+t_{1}(\tilde{x}-r) \cdot A_{1}\left(t_{0}, t_{1}, t^{L}\right)+t_{0} r \cdot\left(\left(1-t^{L}\right) y-c_{0}\left(t_{0}, t_{1}, t^{L}\right)\right.
$$

The government chooses now the tax rates and the public good $g$ in order to maximize the social welfare function:

$$
\Omega=E\left[U\left(c_{0}\left(t_{0}, t_{1}, t^{L}\right), \tilde{c}_{1}\left(t_{0}, t_{1}, t^{L}\right)\right)\right]+E[V(\tilde{g})]
$$

\footnotetext{
${ }^{3}$ See Sandmo (1969), Section 8
} 
given optimal household choice and subject to its budget restriction. We get the following optimization problem:

$$
\max _{t_{0}, t_{1}, t^{L}} E\left[U\left(c_{0}(.), \tilde{c}_{1}(.)\right)\right]+E\left[V(1+r) t^{L} \cdot y+t_{1}(\tilde{x}-r) \cdot A_{1}(.)+t_{0} r \cdot\left(\left(1-t^{L}\right) y-c_{0}(.)\right)\right]
$$

By using optimal household choice (2) and (3), we get as first order conditions:

$$
\begin{aligned}
E\left[-U_{c_{1}} r \cdot s_{0}+V_{g} \cdot\left(\left(t_{1}(\tilde{x}-r) \cdot \frac{\partial A_{1}}{\partial t_{0}}+r \cdot s_{0}+t_{0} r \cdot \frac{\partial c_{o}}{\partial t_{0}}\right)\right]\right. & =0(7) \\
E\left[V_{g} \cdot\left((\tilde{x}-r) \cdot A_{1}+t_{1}(\tilde{x}-r) \cdot \frac{\partial A_{1}}{\partial t_{1}}+t_{0} r \cdot \frac{\partial c_{0}}{\partial t_{1}}\right)\right] & =0(8) \\
E\left[-U_{c_{1}}\left[1+r\left(1-t_{0}\right)\right]+V_{g} \cdot\left(\left[1+r\left(1-t_{0}\right)\right]+t_{1}(\tilde{x}-r) \cdot \frac{\partial A_{1}}{\partial t^{L}}+t_{0} r \cdot \frac{\partial c_{0}}{\partial t^{L}}\right)\right] & =0(9)
\end{aligned}
$$

As $\frac{\partial A_{1}}{\partial t_{1}}=\frac{A_{1}}{1-t_{1}}$ and $\frac{\partial c_{0}}{\partial t_{1}}=0$ from Proposition 1, (8) can be rewritten as:

$$
E\left[V_{g} \cdot(\tilde{x}-r)\right] \cdot \frac{A_{1}}{1-t_{1}}=0
$$

Then, we can conclude:

\section{Proposition 2:}

An optimal income tax system in case of exogenous labor income and risky returns to at least one asset does not tax the safe rate of return $\left(t_{0}=0\right)$. Further, the optimal tax rate on the excess return $(\tilde{x}-r)$ is strictly positive and in the open interval $t_{1} \in(0 ; 1)$, if the households are risk averse in both private and public consumption. The tax on wage income is used to equate marginal utility of public and private consumption in period 1 .

\section{Proof:}

Using (10) in FOC (7) and (9) we obtain $E\left[V_{g}-U_{c_{1}}\right] \cdot r \cdot s_{0}+E\left[V_{g}\right] \cdot t_{0} r \cdot \frac{\partial c_{o}}{\partial t_{0}}=0$ and $E\left[V_{g}-U_{c_{1}}\right] \cdot\left[1+r\left(1-t_{0}\right)\right]+E\left[V_{g}\right] \cdot t_{0} r \cdot \frac{\partial c_{0}}{\partial t}=0$. Combining these expressions results in

$$
t_{0} \cdot r\left(\frac{E\left[V_{g}\right]}{r \cdot s_{0}} \cdot \frac{\partial c_{o}}{\partial t_{0}}-\frac{E\left[V_{g}\right]}{\left[1+r\left(1-t_{0}\right)\right]} \cdot \frac{\partial c_{0}}{\partial t^{L}}\right)=0
$$


and therefore, $t_{0}=0$.

For $t_{0}=0$, from (7) and (9) follows $E\left[U_{c_{1}}\right]=E\left[V_{g}\right]$. Using FOC (3) of the household problem and (10), we can write

$$
E\left[U_{c_{1}} \cdot(\tilde{x}-r)\right]=0=E\left[V_{g} \cdot(\tilde{x}-r)\right]
$$

As $E[Y \cdot Z]=E[Y] \cdot E[Z]+\operatorname{Cov}(Y, Z)$ and $E\left[U_{c_{1}}\right]=E\left[V_{g}\right]$, this expression can be simplified to $\operatorname{Cov}\left(U_{c_{1}}, \tilde{x}\right)=\operatorname{Cov}\left(V_{g}, \tilde{x}\right)$. But, this is only possible for $t_{1} \in(0 ; 1)$.

If $t_{1}$ is set optimally, we have $\operatorname{Cov}\left(U_{c_{1}}, \tilde{x}\right)=\operatorname{Cov}\left(V_{g}, \tilde{x}\right)$. As the households are risk averse in both private and public consumption, in an optimum, the risk must be diversified on both types of consumption. This diversification depends on the relative strength of the risk aversion in private consumption compared to the one in public consumption. Therefore, the tax rate $t_{1}$ depends on this relative risk aversion: The higher the risk aversion in private consumption relative to the one in public consumption, the higher the tax rate on the excess return $(\tilde{x}-r)$.

As the government returns the risk to the households by providing a public good, our result is general and independent of any assumption concerning the ability of the government to deal better with risk than the capital market or not. Further we tax ex-post income. Thus, the government fully participates in all income risk and the critic of Bulow and Summers (1984) does not apply. But, if we assume risk neutrality in public consumption, we get as special case $t_{1}=1$ and all risk is concentrated in public consumption. This would be in accordance with the Arrow-Lind Theorem, where the government can diversify aggregate risk perfectly. Finally, we can state:

\section{Proposition 3:}

If an interest adjusted income tax is implemented, taxing the excess return according to Proposition $2\left(t_{1} \in(0 ; 1)\right)$ and letting the safe component of interest yield tax free $\left(t_{0}=0\right)$, an efficient risk allocation is achieved without disturbing the intertemporal consumption decision. 
There is no trade-off between risk and efficiency in allocation. The marginal rate of time preference equals the safe rate of return $(\rho=r)$.

\section{Proof:}

From (4), the marginal rate of time preference is $\rho=r \cdot\left(1-t_{0}\right)$. For $t_{0}=0, \rho=r$. In the optimum, the marginal rate of time preference is then independent of the tax rates and the intertemporal consumption decision is not distorted. Additionally, $\operatorname{Cov}\left(U_{c_{1}}, \tilde{x}\right)=\operatorname{Cov}\left(V_{g}, \tilde{x}\right)$ assures efficient risk allocation.

As mentioned above, Richter and Wiegard (1991) show that a traditional consumption tax cannot achieve the insurance function of an income tax in case of risky capital income. Richter (1992) shows the same result for a cash-flow tax. But is it true that an income tax does always better? Examining our results, this view must be handled with care.

We use a proportional wage tax on exogenous labor income in the first period. The safe rate of return on savings is tax-free, whereas the excess return or supernormal profits are taxed with a special tax rate. This tax scheme, however, equals a modified consumption-orientated income tax with interest adjustment. ${ }^{4}$ Therefore, we have a consumption tax, which optimally provides insurance against risky capital income and simultaneously avoids a distortion in the intertemporal consumption decision.

This tax scheme can also be named a triple income tax as we divide the full income in three different parts. The excess return (or risk premium) is one of it. This distinction is necessary for achieving an optimal risk allocation by taxation.

The intuition behind these results is straightforward. On the one hand, it is optimal to diversify the aggregate risk between private and public consumption. On the other hand, risk shifting has negative welfare effects by disturbing the intertemporal consumption decision, if we tax the risky asset with only one tax rate. In this case, there is a trade-off and the optimal tax rate depends on the

\footnotetext{
${ }^{4}$ A consumption-orientated income tax with interest adjustment taxes the overall labor income and tax-exempts interest income. For excess returns in capital income a tax with the same tax rate as for labor income is possible. See i.e., Rose 1999, pp. $35 \mathrm{ff}$.
} 
strength of these effects (see i.e., Richter 1992, Richter and Wiegard 1991). If we tax instead the excess return with a special tax rate, the tax system is well defined and the trade-off can be avoided. Thus, we reach both optimal risk allocation and efficiency in intertemporal consumption simultaneously.

\section{Conclusions}

We showed that an interest adjusted income tax can guarantee a welfare maximum in a two-period world with two assets, one of them exhibiting a stochastic return. The excess return must be taxed separately and possible losses in this tax base must be subsidized. In case of risk aversion in public consumption, we have an inner optimum with $t_{1} \in(0 ; 1)$ because the risk must be diversified on both consumption types for having an optimal risk allocation.

As such a tax system is a kind of indirect consumption taxation, we showed that a consumption tax is able to insure against risky interest income.

A disadvantage of our tax system may be that individuals have an incentive to declare labor income as preferred taxed capital income in order to avoid taxes. This problem is similar to the case of a dual income tax with separate tax rates for labor and capital income.

Related work is done in a multi-asset world with a fixed amount of savings. In such a world, Richter (1992) and Christiansen (1993) show that there is a tradeoff between risk allocation and optimal portfolio choice. If the same tax system is introduced as in this paper, this trade-off should also be overcome. ${ }^{5}$ Further work could also examine a multi-asset world with endogenous savings and labor-supply.

\section{References}

Bulow, J. I. and L. H. Summers (1984). The Taxation of Risky Assets. Journal of Political Economy 92, 20-39.

\footnotetext{
${ }^{5}$ See, for example, Hilgers and Schindler (2002) for a first analysis.
} 
Christiansen, V., 1993. A Normative Analysis of Capital Income Taxes in the Presence of Aggregate Risk. The Geneva Papers on Risk and Insurance Theory $18,55-75$.

Eaton, J., Rosen, H.S., 1980. Optimal Redistributive Taxation and Uncertainty. Quarterly Journal of Economics 95, 357-364.

Hilgers, B., Schindler, D., 2002. Shall the Risk Premium be Taxed? Center of Finance and Econometrics, Discussion paper no. 02/17, University of Konstanz.

Richter, W.F., 1992. The Optimal Taxation of Risky Capital Income: An Elasticity Rule. Journal of Economics 55, 101-111.

Richter, W.F., Wiegard, W., 1991. On the Difference between Income and Consumption Taxes when Return to Savings is Uncertain. Recherches Economiques de Louvain 77, 379-390.

Rose, M., 1999. Recommendations on Taxing Income for Countries in Transition to Market Economies. M. Rose (ed.), Tax Reform for Countries in Transition to Market Economies. Lucius \& Lucius, Stuttgart.

Sandmo, A., 1969. Capital Risk, Consumption and Portfolio Choice. Econometrica $37,586-599$.

Sandmo, A., 1977. Portfolio Theory, Asset Demand and Taxation: Comparative Statics with Many Assets. Review of Economic Studies 49, 517-528.

Varian, H.R., 1980. Redistributive Taxation as Social Insurance. Journal of Public Economics 14, 49-68. 